\title{
RESEARCH ON PRESICE POINT POSITIONING AND REAL-TIME KINEMATICS CORRECTIONS FOR UNMANNED AERIAL VEHICLE GLOBAL POSITIONING SYSTEMS
}

\author{
Ugnius RAGAUSKAS ${ }^{1}$, Domantas BRUČAS ${ }^{2}$, Jūratė SUŽIEDELYTE் VISOCKIENE் ${ }^{3}$ \\ ${ }^{1,2}$ Department of Aviation Mechanics, Antanas Gustaitis' Aviation Institute, Vilnius Gediminas \\ Technical University, Vilnius, Lithuania \\ ${ }^{2}$ Space Science and Technology Institute, Vilnius, Lithuania \\ ${ }^{3}$ Faculty of Environment Engineering, Department of Geodesy and Cadastre, Vilnius Gediminas \\ Technical University, Vilnius, Lithuania \\ E-mail: ${ }^{1}$ ugnius.ragauskas@vgtu.lt (corresponding author); ${ }^{2}$ dobr@kmti.lt; ${ }^{3}$ jurate.visockiene@vgtu.lt
}

Received 13 June 2016; accepted 03 March 2017

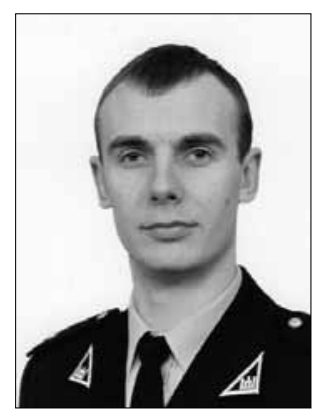

Ugnius RAGAUSKAS. Education: 2013, Master of Transport Engineering, Antanas Gustaitis Aviation Institute, Vilnius Gediminas Technical University.

Affiliations and functions: PhD student at Vilnius Gediminas Technical University, Faculty of Transport Engineering.

Research interests: unmanned aerial vehicles, cargo transportation.

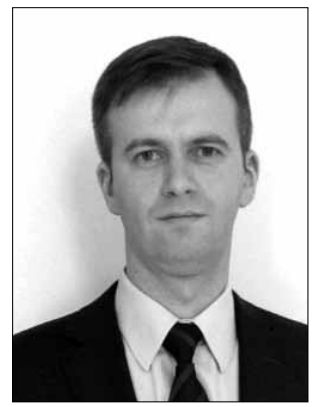

Domantas BRUČAS. Education: 2002, Bachelor of Mechanical Engineering; 2004, Master of Transport Engineering; 2008, Doctor of Measurement Engineering, Vilnius Gediminas Technical University.

Present position: Associated Professor at Vilnius Gediminas Technical University, Director of Space Science and Technology Institute.

Research interests: unmanned aerial vehicles, measurement engineering.

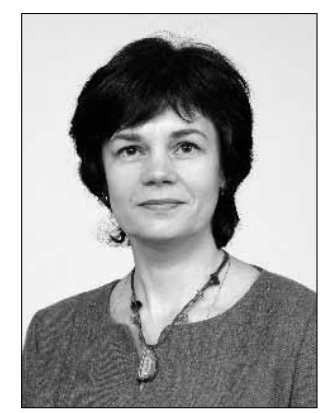

Jūratė SUŽIEDELYTĖ VISOCKIENĖ. Education: Vilnius Gediminas Technical University.

Affiliations and functions: Assoc. Prof. Dr, Head of Department of Geodesy and Cadastre. Research interests: photogrammetry, $3 D$ object modelling, $R P V$.

Abstract. Unmanned Aerial Vehicles (UAVs) are used in different tasks with different flight path accuracy. To achieve a greater accuracy of flight trajectory GPS accuracy improvement methods are analyzed. The present article explains the main principles of GPS measurement. Precise Point Positioning (PPP) and Real-Time Kinematics (RTK) methods are described. and compared. Also, both methods have been tested.

Keywords: UAV, Real-Time Kinematics, post processing, GPS accuracy. 


\section{Introduction}

Unmanned aerial vehicles (UAV) can accomplish a lot of different tasks. Each task requires a different accuracy. To achieve the best accuracy UAVs use Global Navigation Systems (GNSS). GNSS using the GPS (the Global Positioning System), GLONASS, Galileo or Beidou systems are used in many applications. In this case only the GPS will be used. Positioning and navigation are the main applications of GPS usage (Xu 2007)algorithms and applications of the Global Positioning System (GPS/ Galileo. The algorithm to find out a location is used to measure the ranges between receivers and satellites. GPS satellites are broadcasting it onto a position, so the receiver can receive it and calculate the distance. If the position is changing, the receiver can calculate velocities.

\section{The basics of GPS measurement}

GPS satellites transmit all data on three frequencies:

- L1 (1575.42 MHz);

- L2 (1227.60 MHz);

- L5 (1176.45 MHz).

These frequencies are generated by multiplying the $10.23 \mathrm{MHz}$ (the fundamental frequency) by 154, 120 and 115 , respectively (Xu 2007)algorithms and applications of the Global Positioning System (GPS/Galileo. Consider a two dimensional case shown in Figure 1. The points $\mathrm{P} 1, \mathrm{P} 2, \mathrm{P} 3$ are known positions. The "user" position is at point $\mathrm{U}$, where only its distance relative to P1 - P3 is known and denoted as $\mathrm{r} 1-\mathrm{r} 3$. The user's position is constrained to an infinite number of possible locations defined by the circle with its origin at $\mathrm{P} 1$ and radius $\mathrm{r} 1$. If there is a second known location, $\mathrm{P} 2$, and the distance to the user, $\mathrm{r} 2$, is known, this further constrains the user's position to two points located at the intersection of the two circles. A third known location, P3, with a distance r3, uniquely identifies the user's position. Therefore, three known locations and three distances are required to resolve a user's position in this two dimensional case (Al-salihi 2010).

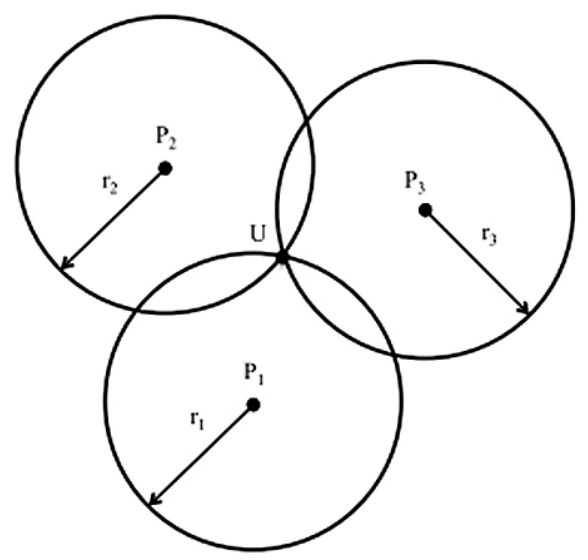

Fig. 1. Two dimensional user postion (Al-salihi 2010)
Similarly, to the two dimensional case, three locations are required to uniquely determine a user's position for a general three-dimensional case. From Figure 1. Two dimensional user postion (Al-salihi 2010), three simultaneous equations can be derived from the Cartesian representation of a sphere, and are given as ), where the location of $\mathrm{U}$ is denoted by $\mathrm{X}_{\mathrm{u}}, \mathrm{Y}_{\mathrm{u}}, \mathrm{Z}_{\mathrm{u}}$ (Tsui 2005; Logsdon 1992):

$$
\begin{aligned}
& \left.r_{1}=\sqrt{\left(x_{1}\right.}-x_{u}\right)^{2}+\left(\mathrm{y}_{1}-y_{u}\right)^{2}+\left(z_{1}-y_{u}\right)^{2} ; \\
& \left.r_{2}=\sqrt{\left(x_{2}\right.}-x_{u}\right)^{2}+\left(\mathrm{y}_{2}-y_{u}\right)^{2}+\left(z_{2}-y_{u}\right)^{2} ; \\
& \left.r_{3}=\sqrt{\left(x_{3}\right.}-x_{u}\right)^{2}+\left(\mathrm{y}_{3}-y_{u}\right)^{2}+\left(z_{3}-y_{u}\right)^{2} .
\end{aligned}
$$

The Carrier phase measurements and Doppler measurements are a classical model for the GPS in standard positioning (Enge, Misra 2006).

\section{Comparison of PPP and RTK post processing techniques}

An autonomous GPS can give us around $15 \mathrm{~m}$ errors, real-time differential stations - about 1-5 m errors, post-processed code differential $-0.5-5 \mathrm{~m}$, and realtime kinematics or precise point positioning - about 0.01-0.02 $\mathrm{m}$ errors. The main reasons for such big errors are:

$\begin{array}{ll}\text { Ionosphere } & 0-30 \text { meters } \\ \text { Troposphere } & 0-30 \text { meters } \\ \text { Measurement Noise } & 0-10 \text { meters } \\ \text { Ephemeris Data } & 1-5 \text { meters } \\ \text { Clock Drift } & 0-1.5 \text { meters } \\ \text { Multipath } & 0-1 \text { meter } \\ \text { Selective Availability } & 0-70 \text { meters }\end{array}$

After post processing, they can be considerably reduced. As mentioned before, two main methods, the RTK and PPP, are used for error reduction. Table 1 shows their main advantages and disadvantages.

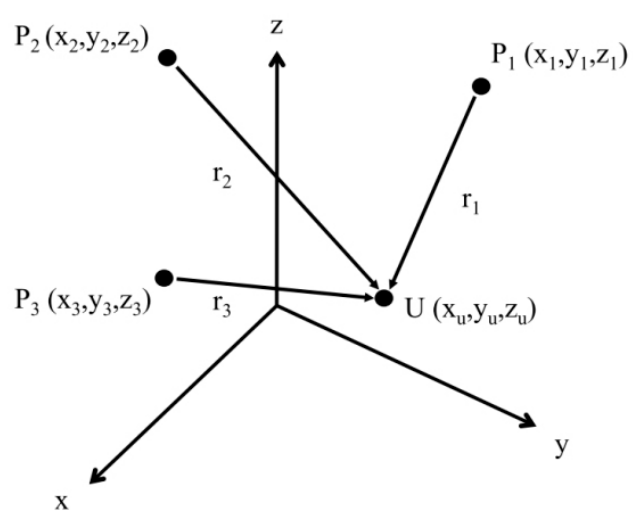

Fig. 2. Three dimensional user position (Al-salihi 2010) 
Table 1. Comparison of RTK and PPP (source: table made by the authors)

\begin{tabular}{|c|c|c|}
\hline & RTK & PPP \\
\hline Advantage & $\begin{array}{l}\text { Immediacy } \\
\text { Better accuracy in the field }\end{array}$ & $\begin{array}{l}\text { Accuracy } \\
\text { Reliability } \\
\text { Free base stations around the world } \\
\text { More control over reference frame of corrected positions }\end{array}$ \\
\hline Disadvantage & $\begin{array}{l}\text { Can be unreliable } \\
\text { Sources not available in all areas } \\
\text { Some sources expensive } \\
\text { Inconsistent reference frames }\end{array}$ & $\begin{array}{l}\text { After the fact } \\
\text { Requires post-processing software }\end{array}$ \\
\hline Applications & $\begin{array}{l}\text { Navigation } \\
\text { Feature verification } \\
\text { When accurate data required in real time }\end{array}$ & $\begin{array}{l}\text { Where accuracy and reliability are the main consideration } \\
\text { When real time accuracy is not so important } \\
\text { When real-time correction sources are not available }\end{array}$ \\
\hline
\end{tabular}

The main difference between the PPP and RTK is the time between the data and products. The RTK provides the result in real-time, whereas the PPP - after data management.

\section{Precise positioning techniques}

Single frequency precise positioning SF-PPP is used in the GNSS community. Three main authors have written about it: (Héroux, Kouba 1995; Ovstedal 2002; Gao et al. 2006). SF-PPP's best accuracy is reached when precise GPS data from a differential station is used: final satellite clocks and orbits, final ionospheric maps, and the latest differential code biases. These products can be downloaded in real-time or at every hour.

Equations (2) and (3) show the pseudorange and carrier phase calculations:

$$
P_{I F}=\frac{f_{1}^{2} \times P_{1}-f_{2}^{2} \times P_{2}}{f^{2}{ }_{1}-f^{2}{ }_{2}}=\rho+c d t+d_{\text {trop }}+d m_{I F}+\varepsilon\left(P_{I F}\right) ;
$$

$$
\phi_{I F}=\frac{f^{2} \times \phi_{1}-f_{2}^{2} \times \phi_{2}}{f^{2}{ }_{1}-f_{2}^{2}} ;
$$

where: Pi indicates pseudorange; $\Phi \mathbf{i}$ - measured carrier phase; $\rho$ - true geometric range; $c$ - speed of light; $d t$ - receiver clock error; $d_{\text {trop }}$ - tropospheric delay; $f$ - frequency; $m_{I F}$ - multipath effect in the measured pseudorange; $\varepsilon\left(P_{I F}\right)$ - measurement noise.

\section{Real-time kinematics techniques}

Real Time Kinematic (RTK) is a technique used for atmospheric errors, satellite orbit error or satellite clock offset error corrections. Two simple receivers of each other can receive the signal at the same time and with the same error. By simply differencing the measurements from both receivers and synchronizing them, spatial errors can be eliminated or reduced. It is very important to have these receivers with a short base line which is less than $10 \mathrm{~km}$. The errors from the receivers become less equal, but this method cannot work properly with long baselines. The algorithm is described in the following equation (4):

$$
\phi=\rho-I+T_{r}+C\left(b_{R x}-b_{\text {Sat }}\right)+N \lambda+\varepsilon_{\phi},
$$

where: $I$ - indicates the signal offset due to the ionosphere; $\operatorname{Tr}$ - signal delay due to the troposphere; $b_{R x}-$ receiver clock offset; $b_{\text {Sat }}$ - satellite clock offset; c speed of light; $\lambda$ - carrier wavelength; $N$ - ambiguity of the carrier-phase; $\varepsilon_{\phi^{-}}$measurement noise; $\rho$ - geometrical range (satellite and receiver).

\section{Methodology}

The study concentrates on hardware and software testing. This study focused on a SwiftNav product, the Piksi module. The study was divided into two modules: one for moving and stationary GPS accuracy. For stationary objects PPP corrections were chosen and RTK for the moving. PPP corrections are available just after the measurement, and special software is needed. Also, it is necessary to download atmospheric corrections from the nearest stations. The biggest advantage of the RTK is the availability to use it in real-time. Therefore, it was used in a moving vehicle, a UAV. The UAV was launched for a short auto mission with 2 different GPS receivers. One of them was employed for getting the RTK corrections and the other one just for the GPS signal. After the flight, a visual point comparison was made.

All the calculation were made by the RTKLIB. The RTKLIB is an open source program package for standard and precise positioning with the GNSS (global navigation satellite system). The RTKLIB consists of a portable program library and several APs (application programs) utilizing the library. It supports standard and precise positioning algorithms with: the GPS, GLONASS, Galileo, QZSS, BeiDou and SBAS. Also it supports various positioning modes with GNSS for both real-time and post-processing, such as: Single, DGPS/DGNSS, Kinematic, Static, Moving-Baseline, Fixed, PPP-Kinematic, PPP-Staticand PPP-Fixed (RTKLIB 2016). 


\section{Experiments of RTK and PPP corrections}

Several experiments related with the GPS accuracy and either RTK or PPP methods were carried out. A PIKSI receiver was used for the experiments (Fig. 3). Piksi receivers are usually used in UAVs or other devices with guidance. Usually aerial surveying demands a high precision GPS/GNSS. The biggest advantage of the RTK is the centimeter-level with a $53 \times 53 \mathrm{~mm}$ form factor.

The first experiment was made using fixed points in well-known places. The portal www.geoportal.lt was used for reference to ground points. 10 measurements in different places were made. The data was collected in about 5 minutes in each point. After that, the data on the ephemeris and clock offsets were taken from "LitPos", stations which are located across the whole country. The map above shows the distribution of station (Fig. 4). They are Lithuanian differential stations across the whole area.

Several points on the ground were chosen. Then the data from differential stations was coolected and the PPP algorithm was used. The comparison of the results shows that there are about a 0.1 second differences. The mean error is about 3 meters, as seen in Table 2. Stationary GPS points (source: table made by the authors).

Table 2. Stationary GPS points (source: table made by the authors)

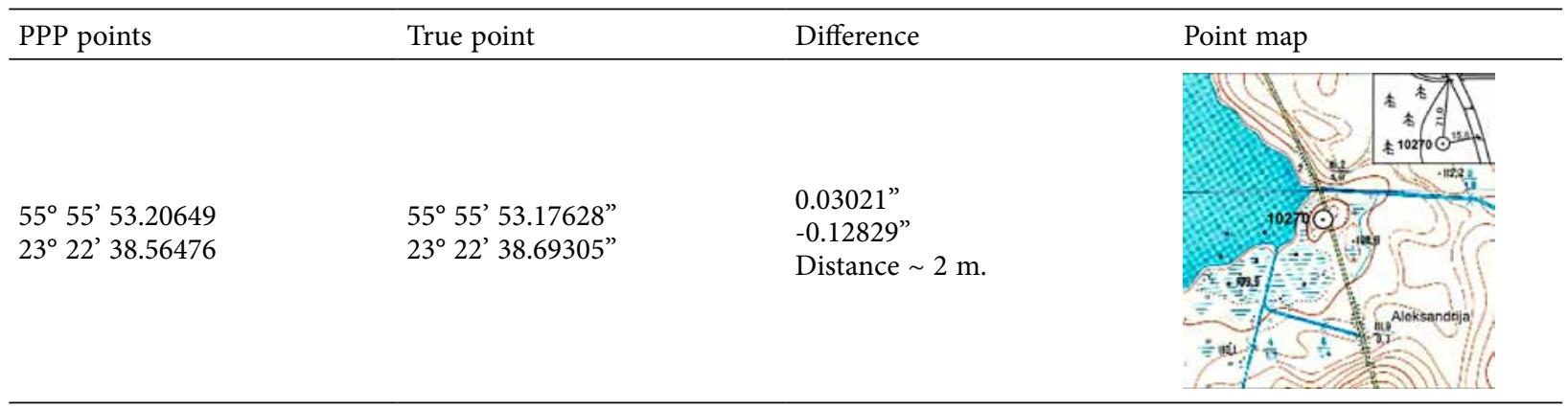
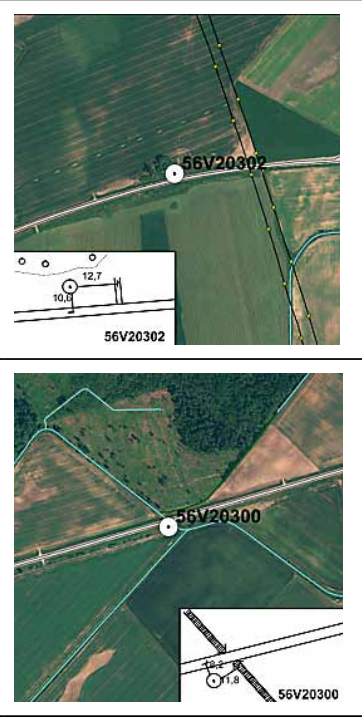

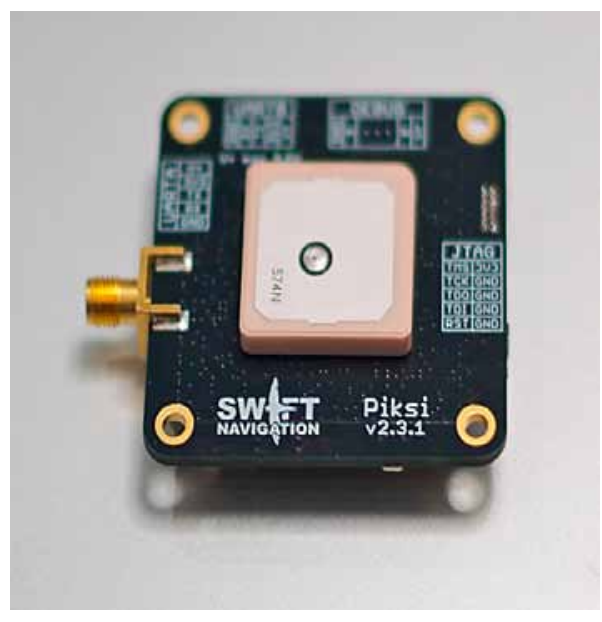

Fig. 3. Swiftnav „Piksi” module (source: figure made by the authors)

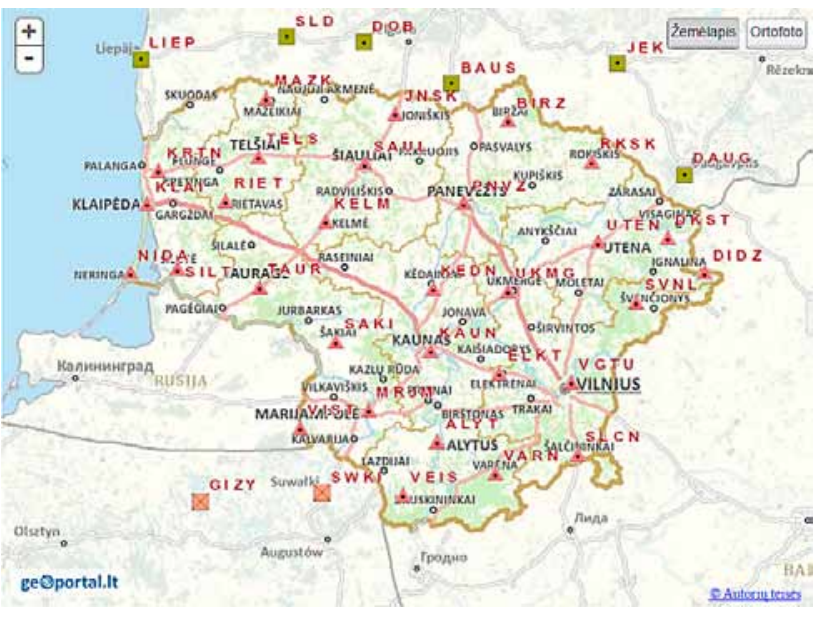

Fig. 4. Distribution of LitPos stations (source: geoportal.lt 2016) 
The error is too big for post processing, but this is probably due to the multipath interference, because all point reference points are underground.

The second experiment was carried out using a moving vehicle - a UAV. A flight with the "Piksi" receiver was done. After using post processing, a lot of GPS points were obtained. These points were compared with those of another GPS receiver (Fig. 5).

As shown in the pictures, not all points were located on the same trajectory. There is a difference of about 1-3 meters. These errors were due to the loss of the connection with the satellite.

The last experiment was also carried out in a fixed position due to the errors of the first and second experiment. This experiment was done in a location with good parameters: location was on the hill; there was clear sky; no obstacles and no metal constructions were present in the area. The data was collected within 10 minutes. Afterwards a PPP algorithm was used. As seen in Figure 6, the points with no PPP algorithms are shown on the left and the figure on the right shows the result after the PPP technique was used. In the first case there were a few meter errors, in the second case the errors were just a few millimeters.

\section{Conclusions}

Technologies like the PPP and RTK are very promising. Using specific algorithms, it is possible to obtain great accuracy. The PPP stands for static points, and is only able to give us the result after some time; however, the results are more reliable and accurate. Without the corrections the GPS scatter was $\pm 5 \mathrm{~m}$, and after the PPP correction - just $\pm 2 \mathrm{~mm}$. This technique can reach a few millimeters, with certain conditions, such as a clear view of satellites, and a good reference station net. The RTK is also a very effective technique. With corrections it is possible to get a scatter of $\pm 10 \mathrm{~cm}$. Moreover, it always operates in real-time, and can provide a better accuracy, especially, if the main stations are close. The problems that arise are to get a good connection of the internet by the GPRS (which is problematic above 100 meters), and to have a dense reference station net. On the plus side,
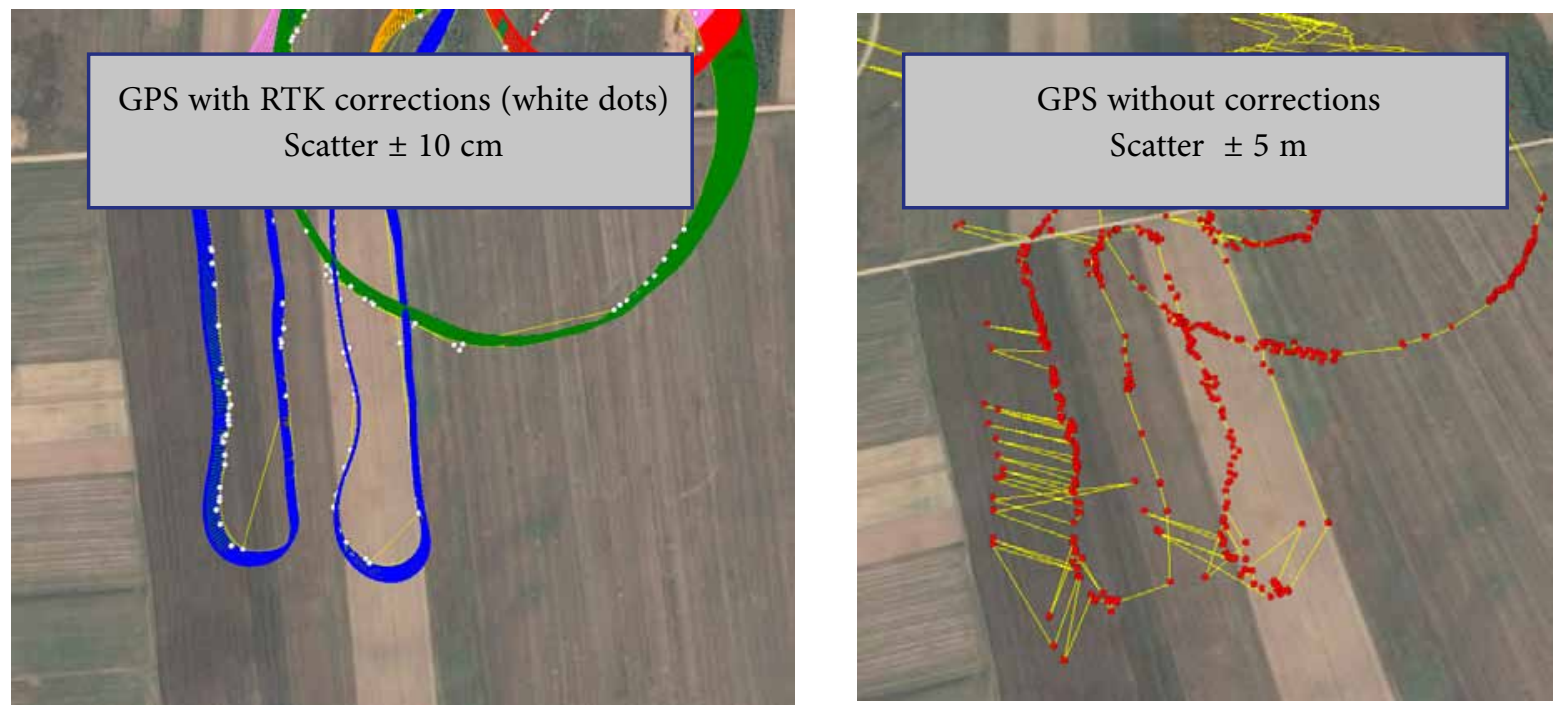

Fig. 5. The same UAV trajectory flight with 2 different GPS receivers (source: figures made by the authors)
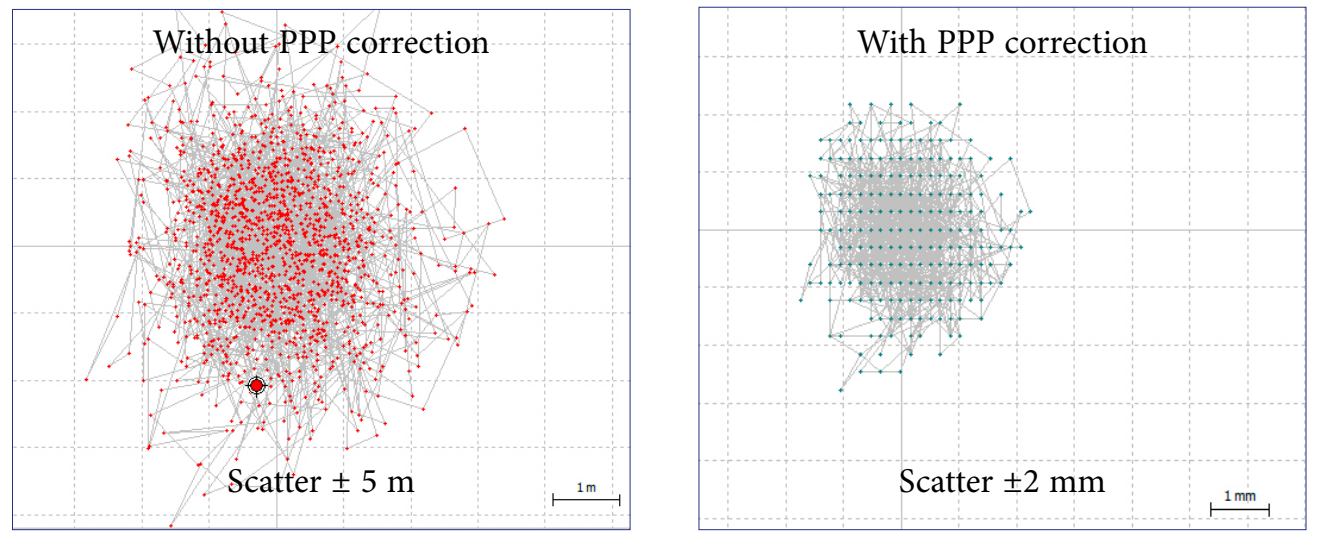

Fig. 6. Fixed point, before the PPP technique and after (source: figures made by the authors) 
these algorithms can be used during the flights; there is just a need for special software and hardware for the calculations to be done inside the vehicle.

\section{References}

Al-salihi, N. K. 2010. Precise positioning in real-time using GPS-RTK Signal for visually impaired people navigation system: PhD thesis. Brunel University School of Engineering, Design.

Enge, P.; Misra, P. 2006. Global positioning system: signals, measurements, and performance. 2 ed. Ganga-Jamuna Press.

Gao, Y.; Zhang, Y.; Chen, K. 2006. Development of a real-time single frequency Precise Point Positioning system and test results, in Proceedings of ION GNSS 2006, 26-29 September 2006, Fort Worth, Texas, 2297-2303.

Geoportal.lt. 2016. Distribution of LitPOS stations, Map of LitPOS [online], [cited October 2016]. Available from Internet: https://www.geoportal.lt/geoportal/web/litpos-en/
Héroux, P.; Kouba, J. 1995. GPS precise point positioning with a difference, in Geomatics'95, 13-15 June 1995, Ottawa, Ontario.

Logsdon, T. 1992. The NAVSTAR global positioning system. Van Nostrand, New York: Springer.

https://doi.org/10.1007/978-1-4615-3104-3

Ovstedal, O. 2002. Absolute positioning with single frequency GPS receivers, GPS Solut 5(4): 33-44. https://doi.org/10.1007/PL00012910

RTKLIB. 2016 RTKLIB software homepage, Overview [online], [cited October 2016]. Available from Internet: http://www.rtklib.com/

Tsui, JBY. 2005. Fundamentals of Global Positioning System receivers: a software approach. 2 nd ed. Hoboken: Wiley.

$\mathrm{Xu}, \mathrm{G} .2007$. GPS: theory, algorithms, and applications. Berlin, Heidelberg: Springer-Verlag Berlin Heidelberg. 